\title{
A Guide to Safety in Dermatologic Cosmetic Procedures: Avoidance and Management of Common Pitfalls and Perils
}

\author{
Daniel Christiansen • William Stebbins
}

Published online: 15 March 2013

(C) Springer Science+Business Media New York 2013

\begin{abstract}
Minimally-invasive cosmetic procedures are commonly performed in the outpatient setting and have rapidly grown in popularity. Botulinum toxin, fillers, sclerotherapy, and lasers are all frequently used to diminish unwanted signs of aging. While these procedures are generally safe in the hands of experienced and knowledgeable providers, complications do occur. The following review article discusses adverse events associated with minimally invasive cosmetic procedures and how best to manage these chance occurrences.
\end{abstract}

Keywords Cosmetic $\cdot$ Procedures · Dermatology ·

Botulinum toxin · Fillers $\cdot$ Hyaluronidase $\cdot$ Sclerotherapy ·

Complications · Adverse events · Treatment · Management

\section{Introduction}

Minimally-invasive cosmetic procedures have experienced unprecedented growth over the past several years. The American Society for Dermatologic Surgery (ASDS) reported that their members performed over 4 million in 2011 alone [1]. The majority of these cosmetic procedures are carried out safely, but they are not without risk. Fortunately, the majority of complications are avoidable or treatable with adequate preparation and foresight.

The initial consultation sets the tone for all subsequent encounters with the patient and is the best opportunity to prevent a number of pitfalls. It is imperative to take a thorough history and assess patient expectations at this visit.

\footnotetext{
D. Christiansen $\cdot$ W. Stebbins $(\bowtie)$

Department of Internal Medicine - Division of Dermatology, Vanderbilt University Medical Center, 719 Thompson Lane, Suite 26300, Nashville, TN 37204, USA

e-mail: William.g.stebbins@vanderbilt.edu

D. Christiansen

e-mail: Daniel.1.christiansen@vanderbilt.edu
}

Any patient misconceptions regarding possible outcomes and overall procedure efficacy should be fully addressed. Patients should be encouraged to remove all makeup and cosmetic products to allow for an unbiased examination. Pictures of the proposed treatment area(s) should be taken, preferably from standardized camera angles, to facilitate future comparisons. Extra time should be allocated to discuss possible treatment options, side effects, and fully answer all patient questions. Full disclosure enables the patient to make an educated decision to minimize the potential for future misunderstandings or dissatisfaction.

In addition to obtaining informed consent, it is imperative that practitioners have an up-to-date and comprehensive understanding of all treatment modalities they employ. The following review presents a brief outline of the most commonly used minimally-invasive cosmetic procedures and products to serve as a reference for the cosmetic dermatologist. Numerous complications and treatment options are discussed to provide the practitioner with a rapid resource for dealing with these rare events.

\section{Botulinum Toxins}

Botulinum toxin injection is the most commonly performed cosmetic procedure reported by ASDS members [1]. The toxin derivatives each work within the presynaptic nerve terminal to inhibit the release of acetylcholine at the neuromuscular junction, thereby stopping muscular contraction. Four types are currently available in the United States, and three of these are approved by the U.S. Food and Drug administration (FDA) for cosmetic use.

The three approved for cosmetic use, onabotulinum, abobotulinum, and incobotulinum, are all based on botulinum toxin A. They enzymatically cleave SNAP-25 to prevent vesicular docking and are approved for the temporary improvement in the appearance of moderate to severe glabellar lines. The onset of action for these products is generally within 
1-2 days, with maximum effect achieved by 7 days, and a total duration of 4 months seen in the majority of patients [2-4]. The fourth product, rimabotulinum toxin, is a type B toxin that enzymatically cleaves a separate component of the docking complex, synaptobrevin. It also results in cessation of muscular contraction, but is not FDA approved for cosmetic use. Table 1 summarizes the four botulinum derivatives currently available in the United States [5-9].

A key concern of practitioners is the overall shelf-life due to the high carrying costs of these products. The manufacturers recommend reconstitution of each single-use vial of toxin with $0.9 \%$ preservative free saline, stored at $2-8{ }^{\circ} \mathrm{C}$ $\left(36-46^{\circ} \mathrm{F}\right.$ ) and used within $4 \mathrm{~h}$ (Onabotulinum toxin $\mathrm{A}$ and Abobotulinum toxin A) or $24 \mathrm{~h}$ (Incobotulinum toxin A) of reconstitution. However, studies have shown that toxin remains efficacious for at least 6-7 weeks after reconstitution with preserved saline when refrigerated at $2-8{ }^{\circ} \mathrm{C}$ and that serial re-extraction of toxin is safe [10].

Botulinum toxin type A products are routinely used "off-label" for treating a variety of locations with dynamic rhytides. These include crow's feet, marionette lines, and forehead creases. The only region that is FDA approved, though, is the glabellar complex. Manufacturers recommend 20 units distributed in 4-unit aliquots to five sites (two injections to each corrugator muscle and one injection to the procerus) for onabotulinum toxin $\mathrm{A}$ and incobotulinum toxin A versus 50 units distributed in 10-unit aliquots over the same five locations for abobotulinum toxin A [5-8].

Botulinum toxin derivatives are generally safe and well tolerated when used at cosmetically approved dosages. Absolute contraindications to injection include overlying infection and known hypersensitivity to any ingredient of the formulations, including cow's milk allergy for abobotulinum toxin A. All three types are pregnancy class $\mathrm{C}$ and are not recommended for lactating or nursing mothers. Relative contraindications include known neuromuscular disorders such as myasthenia gravis, amyotrophic lateral sclerosis, and EatonLambert [5-8]. At least three cases have been reported of myasthenia gravis being unmasked after the use of onabotulinum toxin A and one case of a patient with EatonLambert experiencing worsening of symptoms after the use of onabotulinum toxin A $[11,12]$. Concomitant use of aminoglycosides, spectinomycin, tubocurarine-like compounds that interfere with neuromuscular transmission, anticholinergic drugs, and muscle relaxants are all also considered

Table 1 Botulinum toxin derivatives

\begin{tabular}{|c|c|c|c|c|}
\hline Drug & Trade name & FDA approved indications & Vial contents & Contraindications \\
\hline \multirow[t]{3}{*}{$\begin{array}{l}\text { Onabotulinum } \\
\text { toxin } \mathrm{A}\end{array}$} & Botox & $\begin{array}{l}\text { Temporary improvement in } \\
\text { appearance of moderate to }\end{array}$ & $\begin{array}{l}\text { Available as } 50 \text { or } 100 \text { units } \\
\text { of toxin }\end{array}$ & \multirow[t]{3}{*}{ Absolute: } \\
\hline & Botox & severe glabellar lines. & 100-unit vial contains & \\
\hline & Cosmetic & $\begin{array}{l}\text { Treatment of cervical } \\
\text { dystonia, severe primary } \\
\text { axillary hyperhidrosis, } \\
\text { strabismus, and blepharospasm }\end{array}$ & $\begin{array}{l}0.5 \mathrm{mg} \text { albumin, and } \\
0.9 \mathrm{mg} \text { sodium chloride }\end{array}$ & \\
\hline \multirow[t]{3}{*}{$\begin{array}{l}\text { Abobotulinum } \\
\text { toxin A }\end{array}$} & \multirow[t]{3}{*}{ Dysport } & $\begin{array}{l}\text { Temporary improvement in the } \\
\text { appearance of moderate to } \\
\text { severe glabellar lines }\end{array}$ & \multirow{2}{*}{$\begin{array}{l}\text { Available as } 300 \text { or } 500 \text { units } \\
\text { of toxin (equivalent efficacy } \\
\text { at 2:5-3:1 units when } \\
\text { compared to Botox (Karsai } \\
\text { 2009) }\end{array}$} & $\begin{array}{l}\text { the formulations } \\
\text { (includes cow's milk } \\
\text { allergy for Dysport) }\end{array}$ \\
\hline & & & & - Pregnancy category C \\
\hline & & Treatment of cervical dystonia & $\begin{array}{l}125 \mathrm{mcg} \text { human serum } \\
\text { albumin and } 2.5 \mathrm{mg} \text { lactose } \\
\text { (cow milk protein) }\end{array}$ & $\begin{array}{l}\text { - Not recommended for } \\
\text { nursing mothers }\end{array}$ \\
\hline \multirow[t]{3}{*}{$\begin{array}{l}\text { Incobotulinum } \\
\text { toxin A }\end{array}$} & \multirow[t]{3}{*}{$\begin{array}{l}\text { Xeomin (Merz } \\
\text { Pharmaceuticals) }\end{array}$} & $\begin{array}{l}\text { Temporary improvement in } \\
\text { appearance of moderate to severe }\end{array}$ & $\begin{array}{l}\text { Available as } 50 \text { or } 100 \text { units } \\
\text { of toxin }\end{array}$ & \multirow{4}{*}{$\begin{array}{l}\text { Relative: } \\
\text { - History of myasthenia } \\
\text { gravis, amyotrophic } \\
\text { lateral sclerosis, and/or } \\
\text { Eaton-Lambert } \\
\text { - Currently taking } \\
\text { aminoglycosides, } \\
\text { spectinomycin, } \\
\text { tubocurarine- } \\
\text { ike compounds, } \\
\text { anticholinergic drugs, } \\
\text { or muscle relaxants }\end{array}$} \\
\hline & & $\begin{array}{l}\text { glabellar lines associated with } \\
\text { corrugator and/or procerus muscle } \\
\text { activity in adult patients. Treatment } \\
\text { of blepharospasm in adults }\end{array}$ & $\begin{array}{l}\text { 100-unit vial contains } 1 \mathrm{mg} \text { of } \\
\text { human albumin, and } 4.7 \mathrm{mg} \\
\text { sucrose }\end{array}$ & \\
\hline & & $\begin{array}{l}\text { previously treated with Botox and } \\
\text { cervical dystonia }\end{array}$ & & \\
\hline $\begin{array}{l}\text { Rimabotulinum } \\
\text { toxin B }\end{array}$ & Myobloc & Treatment of cervical dystonia & $\begin{array}{l}17,500 \text { units in a } 3.5-\mathrm{mL} \text { solution } \\
\text { of } 0.05 \% \text { human serum } \\
\text { albumin, } 0.01 \mathrm{M} \text { sodium } \\
\text { succinate, and } 0.1 \mathrm{M} \text { sodium } \\
\text { chloride }\end{array}$ & \\
\hline
\end{tabular}

Bold applies to all of the toxins listed 
relative contraindications to botulinum toxin use due to concern for toxin potentiation [5-8]. The possibility of drug interactions is actually a theoretical risk, as no formal drug interaction studies have been conducted for any of the botulinum toxin-derived products.

Adverse reactions may occur with the use of these products, but they are generally not severe. The most commonly reported reaction experienced by patients is injection site pain. The manufacturer recommendation for reconstitution of product is with $0.9 \%$ preservative free saline, as stated above. Allen et al. 2012 demonstrated a significant decrease in injection site pain with the use of benzyl-alcohol-preserved saline. This is thought to be due to an anesthetic effect directly related to the benzyl-alcohol and may not apply for all types of preserved saline [13•]. The next most common reactions reported with the use of onabotulinum toxin A are diplopia, headache, and fever/malaise [14]. Up to $7.1 \%$ of patients in some studies have reported experiencing such symptoms after injection with toxin, which was significantly higher than those receiving placebo [5-8].

Eyelid ptosis is an uncommon adverse event that may occur when botulinum toxin spreads to the levator palpebrae superioris. Ptosis may occur up to 2 weeks after injection and up to $1 \%$ and $5 \%$ incidences have been reported with glabellar and forehead injections $[15,16]$. Prevention is the most important consideration to avoid this complication. Injections should be performed greater than $1 \mathrm{~cm}$ above the brow without crossing the midpupillary line laterally [14]. If ptosis does occur, then apraclonidine $0.5 \%$ eye drops may be considered for treatment. Apraclonidine is an alpha-2-adrenergic agonist that results in contraction of the Muller muscles with subsequent elevation of the upper eyelid. The most common dosing scheme is $2-3$ drops daily to the affected eye until ptosis resolves [16, 17].

Severe adverse reactions are fortunately rare, with botulinum toxin derivatives at approved doses. Potentially lifethreatening distant spread of toxin after local injection, prolonged generalized weakness, and 28 deaths have all linked to therapeutic use of botulinum toxin derivative onabotulinum toxin A $[14,18]$. Therapeutic doses are much higher than those approved for cosmetic use and range from a maximum dose of 350 units of onabotulinum toxin $\mathrm{A}$ for cervical dystonia to 1,000 units of abobotulinum toxin A for the same indication $[5,6]$. Dermatologic use of onabotulinum toxin A for cosmesis at approved doses has never been reported to result in distant spread or death [9].

\section{Fillers}

Fillers are the second most frequently used products by the cosmetic dermatologist. There are a wide variety of FDAapproved types that are currently available on the market.
Table 2 lists the most common types [19-22]. Each category varies in its effective duration, composition, and use criteria. With the exception of polymethylmethacrylate beads, which are considered permanent, all FDA-approved fillers are absorbable. Silicone gel and liquid silicone are also permanent but not FDA-approved for cosmetic use.

Filler use is generally safe with the use of proper technique and awareness of anatomic danger zones. The most common complications reported for all filler types are injection site reactions. These include swelling, redness, tenderness, and bruising [23]. The reactions generally last 4 5 days and can be minimized with proper injection techniques. Rapid injection, fan-like needle use, and increased volumes have all been shown to increase the incidence of these reactions [24]. Minimizing dissection of the subepidermal plane, use of blunt tip cannulas, and use of subcutaneous injection is recommended. The risk of bruising may also be minimized by counseling patients to avoid prescription and over-the-counter blood thinners. These include nonsteroidal anti-inflammatories and supplements which should be discontinued 7 days prior to procedure if possible [25].

Injection site pain is also common with fillers, and a wide variety of anesthetic options are available to maximize patient comfort. The use of a gel ice pack prior to injecting a local anesthetic, usually lidocaine, is recommended [22, 26]. In patients receiving lip augmentation, a topical anesthetic may also be applied to the perisulcular region for $5 \mathrm{~min}$ prior to injection of lidocaine into the gingival sulcus $(0.2 \mathrm{ml}$ at four to five points) to minimize discomfort [26].

Topical anesthesia is another option for dealing with injection site pain and has proven useful for a wide variety of cosmetic procedures. There are multiple FDA-approved anesthetics available. The most widely used is EMLA, a prescription only eutectic mixture of $2.5 \%$ lidocaine and $2.5 \%$ prilocaine. Anesthesia occurs to a maximum depth of $5 \mathrm{~mm}$ within $120 \mathrm{~min}$. Over-the-counter lidocaine formulations are also available, including: LMX ( 4 or $5 \%$ lidocaine liposomal cream), Topicaine $4 \%$ or $5 \%$ lidocaine gel, and Lidoderm (5\% lidocaine patch) [27••]. It is extremely important to instruct patients on the appropriate application of these medications and warning signs of toxicity which include tinnitus, perioral numbness, nystagmus, and slurred speech. Non-FDA approved compounded medications may increase risk of adverse events due to variable medication potencies. Rare deaths have been reported after application of topical anesthetics to large surface areas prior to cosmetic procedures, so care should be exercised when using these products $[28,29]$.

Severe reactions and complications to fillers are rare, but practitioner awareness is critical to properly manage them. Perhaps the most worrisome of all filler complications is vascular occlusion. This may result from vessel compression or direct intravascular injection $[30,31 \bullet \bullet$. The glabella 
Table 2 FDA approved fillers

\begin{tabular}{|c|c|c|c|c|}
\hline Filler T six points type & Trade names & FDA approved indications & Duration & Derived from \\
\hline $\begin{array}{l}\text { Hyaluronic acid with } \\
\text { lidocaine }\end{array}$ & $\begin{array}{l}\text { Restylane-L gel, Prevelle } \\
\text { Silk, Elevess }\end{array}$ & $\begin{array}{l}\text { Mid to deep dermal injection } \\
\text { Correction of moderate to } \\
\text { severe facial wrinkles/ } \\
\text { folds and lip augmentation } \\
{ }^{\text {a }} \text { Lip augmentation in } \\
\text { patients over } 21 \text { years old }\end{array}$ & 6-12 months & $\begin{array}{r}\text { Bacteria or avian } \\
\text { (rooster combs) }\end{array}$ \\
\hline $\begin{array}{l}\text { Hyaluronic acid } \\
\text { (polysaccharide) }\end{array}$ & $\begin{array}{l}\text { Belotero balance, Captique } \\
\text { injectable gel Restylane } \\
\text { injectable gel, Perlane, } \\
\text { Juvederm XC, Hylaform }\end{array}$ & $\begin{array}{l}\text { Mid to deep dermal } \\
\text { injection } \\
\text { Correction of moderate to } \\
\text { severe facial wrinkles/folds } \\
{ }^{\text {a }} \text { Lip augmentation in } \\
\text { patients over } 21 \text { years old }\end{array}$ & 6-12 months & $\begin{array}{r}\text { Bacteria or avian } \\
\text { (rooster combs) }\end{array}$ \\
\hline Collagen & $\begin{array}{l}\text { Cosmoderm and Cosmoplast, } \\
\text { Fibrel, Zyderm and Zyplast }\end{array}$ & $\begin{array}{l}\text { Correction of moderate to } \\
\text { deep facial wrinkles } \\
\text { correction of soft tissue contour } \\
\text { deficiencies including acne scars }\end{array}$ & $3-4$ months & $\begin{array}{l}\text { Human or bovine } \\
\text { cell lines }\end{array}$ \\
\hline $\begin{array}{l}\text { Calcium hydroxyl } \\
\text { apatite }\end{array}$ & Radiesse & $\begin{array}{l}\text { Subdermal implantation } \\
\text { for moderate to severe } \\
\text { facial wrinkles } \\
\text { Restoration and/or correction of } \\
\text { signs of lipoatrophy for HIV }\end{array}$ & $12-18$ months & $\begin{array}{l}\text { Mineral } \\
\text { suspended in } \\
\text { gel-like solution }\end{array}$ \\
\hline Poly-L-lactic Acid & Sculptra aesthetic & $\begin{array}{l}\text { Facial lipoatrophy in } \\
\text { patients with HIV }\end{array}$ & 24 months & $\begin{array}{l}\text { Degradable man- } \\
\text { made polymer }\end{array}$ \\
\hline $\begin{array}{l}\text { Polymethylmethacrylate } \\
\text { beads, collagen (bovine) } \\
\text { and lidocaine }\end{array}$ & Artefill & ONLY for nasolabial fold & $\begin{array}{l}\text { Indefinite } \\
\quad \text { (nonabsorbable) }\end{array}$ & $\begin{array}{l}\text { Nonbiodegradable } \\
\text { man-made } \\
\text { polymer }\end{array}$ \\
\hline
\end{tabular}

${ }^{\text {a }}$ Only Restylane-L and Restylane are FDA approved for lip augmentation in patients $>21$ years old

${ }^{\mathrm{b}}$ Liquid silicone and silicone gel are NOT FDA approved for cosmetic use. All use of these products is considered off-label

has been reported to be at higher risk for vascular compromise, and caution is advised if filler is used here [32]. There is an increased risk for retinal embolization when filler is used in the glabella, with at least 32 cases of iatrogenic retinal artery occlusion reported [33•]. A study of 12 consecutive cases showed that 7 occurred after injection into the glabella, 4 into the nasolabial fold, and 1 case involved both sites. Autologous fat accounted for 7 of the cases, HA fillers for 4 cases, and collagen for 1. Each patient experienced sudden visual loss $+/-$ ocular pain in the affected eye [34•]. The proposed mechanism of retinal artery occlusion is retrograde flow of filler material. In the glabella, the occlusion of the retinal or ophthalmic arteries may occur via the supratrochlear or supraorbital arteries. In the nasolabial fold, the retrograde flow may occur via the angular and dorsal nasal artery anastomoses resulting in embolism to the ophthalmic artery, as shown in Fig. 1 [34•]. Seven cases of cerebral infarction have also occurred in the setting of retinal artery occlusion. Each has occurred with the injection of autologous fat [34•].

When injecting into these areas it is extremely important to inject slowly, less than 1 cc per minute, with a small caliber syringe to decrease the chance of exceeding arterial pressure and causing retrograde flow. A case report also identified the vaginal wall as a danger zone after an unlicensed provider performed non-FDA approved vaginal augmentation with $5 \mathrm{~mL}$ of $\mathrm{HA}$ on a patient there. The patient subsequently developed nonthrombotic pulmonary embolization due to the large venous plexus located in this region [35].

The cosmetic practitioner should be familiar with the warning signs of vascular occlusion to aid in management. Rapid identification of potential occlusion is extremely important to minimize poor outcomes. Warning signs of impending occlusion and necrosis include white or bluish discoloration with a reticulated appearance, with or without pain, that occurs seconds to hours after injection [31••, 32, $36,37]$. The primary treatment considerations in this setting include dilation of vasculature, minimization of compression, and decreasing potential for thrombus formation. Vascular dilation may be increased by immediately applying warm compresses and a half-inch of nitroglycerin $2 \%$ paste or a transdermal patch [37]. Nitroglycerin paste may be used every $4 \mathrm{~h}$ if the patient does not develop associated lightheadedness or headaches [31••]. Sildenafil $50 \mathrm{mg}$ daily may also be added, but it increases the risk of side effects when used in conjunction with nitroglycerin paste. Minimizing compression is accomplished by decreasing the filler 
Fig. 1 Illustration of arterial supply to the face in relation to cosmetic filler injection sites.

The supratrochlear and supraorbital arteries are the possible inlets for retrograde flow in the glabellar region. The anastomosis of the dorsal nasal artery from the ophthalmic artery, angular artery, and lateral nasal artery from the facial artery is the possible inlet for retrograde flow in the nasolabial fold. The arrows indicate the route of retrograde flow of embolic materials. Reprinted from [34•] with permission from Elsevier

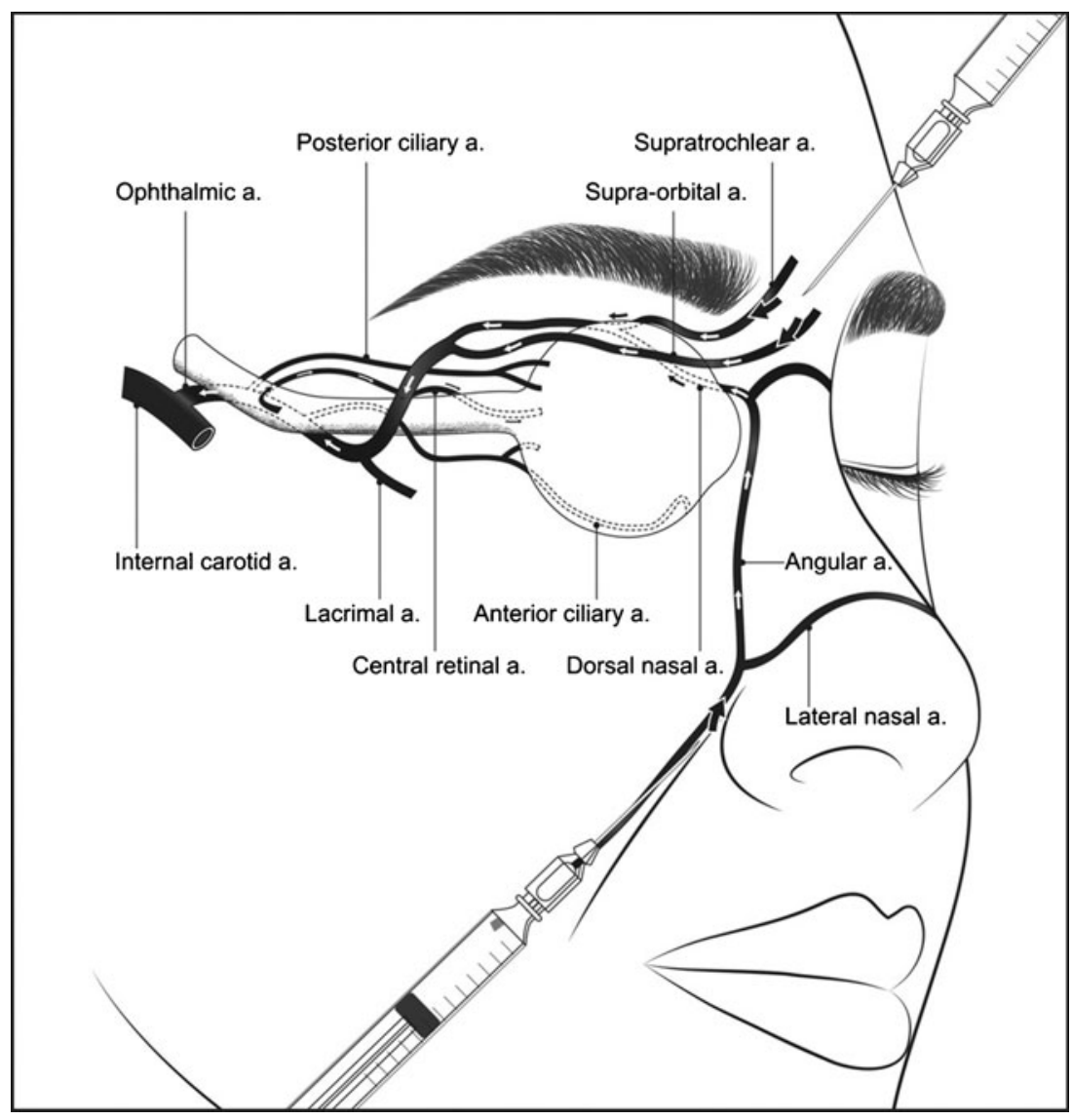

amount if possible. Hyaluronidase may be used for HA fillers, or incision and drainage of other types can be attempted. In the setting of impending necrosis, the recommended dosage of hyaluronidase is 10-75 units daily until resolution [36]. Reduction of vascular compartment pressure by using a short course of corticosteroids is recommended [31••]. It is important to minimize platelet aggregation and thrombi by giving patients immediate sublingual aspirin, followed by aspirin $81 \mathrm{mg}$ daily [31••]. If vascular occlusion occurs, it is important to carefully monitor patients and ensure close follow-up. Table 3 summarizes the proposed management of suspected vascular occlusion related to fillers. After an occlusive episode occurs, the patient may experience sloughing of overlying skin with erosions. If there is any evidence concerning for infection, such as vesiculation or increased warmth, consider obtaining cultures and starting patient on appropriate antibiotic therapy. Postinflammatory hyperpigmentation and subsequent scarring may occur.

Another important potential filler complication is nodule formation [38]. Injection of filler too superficially is a frequent cause. Hyaluronic and poly-l-lactic acid may result in blue nodules due to the Tyndall effect while calcium hydroxylapatite may cause white nodules when placed superficially. Of note, calcium hydroxylapatite is not FDAapproved for use in the lips, and even if injected in an appropriate deep plane, it may migrate superficially and result in nodule formation [23]. Caution is also advised when injecting periorbitally due to the thin skin and risk of superficial placement. Lump and bump formation may occur and the duration of fillers is often prolonged due to decreased metabolism in this area [30].

When patients develop noninflammatory nonpainful nodules, treatment options vary depending on filler type. If they occur after injection of hyaluronic acid fillers, the site should be thoroughly massaged and a waiting period of $1-$ 2 weeks is recommended [39]. If the nodules persist then hyaluronidase may be used [40]. Hyaluronidase causes enzymatic degradation of hyaluronic acid via hydrolysis [41••]. The three FDA-approved types of hyaluronidase currently marketed are Vitrase (ISTA Pharmaceuticals), Amphadase (Amphastar pharmaceuticals), and Hylenex (Halozyme Therapeutics) [42-44]. They are all approved for use with subcutaneous fluid administration, to increase dispersion of injected drugs, and to improve resorption of radiopaque agents [42-44]. Vitrase and Amphidase are supplied in 2-mL singledose vials with 200 units $/ \mathrm{mL}$ and 150 units $/ \mathrm{mL}$, respectively. Hylenex is supplied in $1-\mathrm{mL}$ vials with 150 units $/ \mathrm{mL}$. The use of hyaluronidase to resorb hyaluronic acid containing fillers is considered 'off-label.' They are best used within $12 \mathrm{~h}$ of opening and resolution of filler nodules takes an average of 
Table 3 Management of fillerinduced vascular occlusion

\begin{tabular}{ll} 
Dilate vasculature & $\begin{array}{l}\text { Apply warm compresses to site } \\
\text { Apply one-half to } 1 \text { inch of nitroglycerin } 2 \% \text { paste and massage every } 4 \mathrm{~h} \\
\text { Consider adding sildenafil } 50 \mathrm{mg} \text { daily for 3-5 days (increased risk of side } \\
\text { effects when added to nitroglycerin) }\end{array}$ \\
$\begin{array}{l}325 \mathrm{mg} \text { of sublingual aspirin immediately followed by } 81 \mathrm{mg} \text { by mouth daily } \\
\text { Prevent thrombus } \\
\text { Mormation }\end{array}$ & $\begin{array}{l}\text { Hyaluronidase allergy skin testing followed by administration of } 10-75 \text { Units } \\
\text { daily until resolution with HA fillers } \\
\text { Consider course of prednisone } 20-40 \mathrm{mg} \text { daily or equivalent for 3-5 days }\end{array}$ \\
\hline
\end{tabular}

Adapted from $[30,31 \bullet \bullet, 32,37]$

injection to minimize bacterial load. Injecting through inflamed skin is an absolute contraindication for all fillers. When a painful nodule develops within the first 2 weeks, post-injection hyaluronidase should be used to dissolve any HA fillers and incision and drainage should be employed to remove fillers for culture [39]. Patients should then be started on a course of antibiotics. Clarithromycin $500 \mathrm{mg}$ twice daily for 2 to 6 weeks has been recommended to cover rapidly growing mycobacteria [38]. Minocycline $100 \mathrm{mg}$ twice daily is an additional consideration to cover the majority of skin flora and provide an anti-inflammatory effect [39, 47, 49]. Antibiotics should ultimately be tailored to culture results. When a painful or inflammatory nodule occurs in the intermediate ( 2 weeks-1 year) or delayed ( $>1$ year) time-frame, a biofilm is most likely [38]. Biofilms are composed of adherent aggregates of bacteria in an extracellular matrix that makes culture and treatment exceedingly difficult [50•]. They are most common with long-acting absorbable and permanent fillers [39]. An incision and drainage should be performed to obtain material for culture and the patient placed on concurrent antibiotic therapy, such as a macrolide and tetracycline [49]. Once antibiotics are started, intralesional steroids may again be considered to help reduce the size of granulomas [39, 49]. The recommended dosages of intralesional triamcinolone reported in this setting range from $2.5 \mathrm{mg} / \mathrm{mL}$ to $40 \mathrm{mg} / \mathrm{mL}$ $[38,39,49]$. If improvement is not noted, then a full excision of the filler and biofilm with or without antibiotic irrigation to the site may be required [39]. Laser-assisted removal of recalcitrant nodules, including infectious ones, utilizing a 532-nm laser and an 808-nm diode laser has also been reported [51].

\section{Sclerotherapy}

Sclerotherapy is a commonly used method to treat unwanted leg telangiectasias $(0.1-1 \mathrm{~mm}$ in diameter) and reticular veins (1-3 $\mathrm{mm}$ in diameter). Multiple types of sclerosants are utilized in the United States, and two are FDA approved for this indication. The most common sclerosant used worldwide, hydroxy polyethoxydodecane (Polidocanol; POL), was FDA approved in 2010. It acts as a detergent to strip the lipid membrane from vessel walls, resulting in collapse and 
subsequent thrombosis. POL has a shelf life of 3 years when stored at $59-86^{\circ} \mathrm{F}$ and is contraindicated in pregnant or breastfeeding women. The main advantage of POL over other sclerosants is a decreased risk for tissue necrosis and less pain with injection [52••]. POL was originally produced as a topical anesthetic and results in less pain than other sclerosants due to its anesthetic action [53]. Mild tissue urtication may occur after using POL and be relieved with application of ice [52••]. Sodium tetradecyl sulfate (Sotradecol; STS) is another commonly used sclerosant that was FDA approved in 2006. It also has a detergent action to promote vessel wall collapse. Contraindications for the use of STS include pregnancy, breastfeeding, and patients with a history of asthma or multiple allergies. Hypertonic sodium chloride $20 \%$ or $23.4 \%$ solution is a non-FDA approved sclerosant utilized for sclerotherapy. Its mechanism of action differs from POL and STS, with the hyperosmolar solution disrupting cellular membranes causing vessel collapse and hemolysis. The main drawback of hypertonic saline is an increased risk for pain, necrosis, and hyperpigmentation [53].

The most common complication occurring after sclerotherapy is hyperpigmentation. It may develop in up to $10-30 \%$ of patients within 3-4 weeks of therapy. Spontaneous resolution occurs in $70 \%$ of patients over 6 months, but it may persist greater than 1 year in $10 \%$ of patients $[54,55]$. Risk factors for hyperpigmentation include: high sclerosant concentrations, superficial vessels, darker skin types, and location below the thighs. The use of $30-40-\mathrm{mmHg}$ graduated compression stockings immediately following sclerotherapy for a minimum of 1 week, and preferably up to 4 weeks, is recommended to help reduce pigmentation and telangiectatic matting [56]. Microthrombectomy, utilizing a No. 65 beaver blade to create stab incisions $3-5 \mathrm{~mm}$ apart along thrombosed vessels, was shown in a single randomized controlled trial to help reduce hyperpigmentation as well [55].

Treatment options for post-sclerotherapy hyperpigmentation are limited. Topical chemical peels and bleaching agents have been utilized in the past, but laser therapy is considered more efficacious. One small study showed improvement in postsclerotherapy hyperpigmentation with the Q-switched ruby (694-nm) laser [57]. Success at minimizing hyperpigmentation has also been anecdotally reported with the use of a blended Q-switched 532-nm/1,064-nm laser at 4-7 J/ $\mathrm{cm}^{2}$ [54].

Uncommon reactions seen with sclerosants include ulceration and thrombosis. Ulceration tends to occur with poor injection technique resulting in extravasation of sclerosant. This may cause overlying tissue necrosis and is more common with hypertonic saline than STS and POL. Necrosis is often heralded by pain, petechiae, and blanching. It is important to use proper technique, low volumes and low concentrations to minimize this complication [52••].

Thromboembolism and cerebrovascular incidents are exceedingly uncommon with sclerosants but have been reported.
The most common culprit is the use of sclerosant foam - a mixture of air, carbon dioxide, or carbon dioxide-oxygen, $3: 1-4: 1$ with detergent. The foam increases detergent potency two to four times by displacing blood and maximizing surface area $[52 \bullet \cdot]$. An increased risk of embolization has been reported with foam and some practitioners advocate using smaller volumes, $<10 \mathrm{~mL}$, per treatment session to minimize risk [58]. No studies currently exist to demonstrate whether this approach actually decreases embolization. Rare reports exist of patients having blindness and stroke after sclerotherapy secondary to embolism through a patent foramen ovale (PFO), but the routine use of transthoracic echocardiography in sclerotherapy patients is likely cost-prohibitive $[58,59]$. Signs of embolism include chest tightness, dry cough, dizziness, and visual disturbances. These symptoms are generally transient. In one small case series, the incidence of respiratory side effects varied by the type of gas/mixture utilized to create the foam [60]. Chest tightness in this series ranged from $0 \%$ to $3.1 \%$ to $18 \%$ depending on whether patients received foam polidoconal mixed with carbon dioxide-oxygen, carbon dioxide, or air, respectively. Anaphylactic shock has also occurred with the use of sclerosants, with five known deaths, and a reported incidence of $0.3 \%[52 \bullet \bullet, 61]$.

\section{Lasers}

A wide variety of lasers and intense pulsed light (IPL) devices are available for cosmetic photorejuvenation, treatment of unwanted vascular lesions, and hair removal. Safety is a paramount concern when using these devices, and a thorough understanding of the risks associated with their use is extremely important.

Prevention of ocular damage is a particular concern with any light-based treatment modality. Injury to the lens and/or cornea may occur secondary to ultraviolet, midinfrared, and far-infrared wavelengths $(200-400 \mathrm{~nm}, 1,400-3,000 \mathrm{~nm}$, and $3,000-10,600 \mathrm{~nm}$ ). Retinal and choroid injury may occur with both visible and near-infrared wavelengths $(400-760 \mathrm{~nm}$ and $760-1,400 \mathrm{~nm}$ ). Protective eyewear should be chosen based on laser wavelength, and the maximum optical density (OD) should be chosen that still allows adequate vision for the procedure. Do not use chlorhexidine to sterilize eyewear or for use prior to laser therapy. Chlorhexidine may cause corneal ulcerations and be aerosolized in laser plumes [62, 63]. Use of alcohol to cleanse the skin should also be avoided because of its incendiary potential.

Multiple other preventable hazards are associated with the use of this equipment. Patient dentition must be protected, as enamel is sensitive to the effects of ultraviolet and infrared light. Patients should be advised to keep their mouth closed during the procedure or have a moistened gauze covering applied over their teeth. Due to the high 
energy utilized with most laser systems, they should not be employed around flammable objects. Dry gauze, towels, face masks $/ \mathrm{O}_{2}$ cannulas, makeup, hairspray, dry hair, and alcohol are all potentially combustible. A water and fluorohydrocarbon fire extinguisher (will not damage laser components) should be readily available to put out any fires, including electrical, that may occur with laser use. Only experienced and authorized technicians should work on lasers and IPL devices to minimize chance of electrocution secondary to high-voltage and highcurrent inherent in laser operation. Adequate smoke exhaust is essential in laser rooms as carcinogenic, respiratory irritants, and infectious agents may be present in laser plumes. Plumes from carbon dioxide lasers have contained carbon monoxide, hydrogen cyanide, ammonia, formaldehyde, acrolein, toluene, and benzene. Patients, staff, and practitioners should wear high-filter masks as human papillomavirus and human immunodeficiency virus have been identified in plumes. No reported cases of contracting HIV from plume smoke have occurred, but evidence strongly suggests type 6 and 11 human papillomavirus may be transmitted. A single case report of a laser surgeon contracting laryngeal papillomatosis after treating anogenital condyloma and anecdotal reports of operators contracting nasopharyngeal verrucae lends credence to this hypothesis [62, 63, 64••, 65].

The most commonly reported adverse reactions to laser therapy are erythema and edema, which typically remit within several hours after treatment [65]. Patients should be counseled that crusting and weeping may last 3-4 days with AFL, bright erythema may persist up to 7 days, and a low-level of erythema may last upwards of 1 month with aggressive AFL treatments. If edema is problematic for the patient, a five day course of prednisone may be provided to facilitate resolution. Transient urticaria may also occur, especially in patients with a history of hives. Treatment recommendations include the use of ice packs, antihistamines, and reassurance [66].

Erosions and crusting may also occur and are most common with fractional ablative and non-ablative laser therapy. Posttreatment use of moisturizers and cool soaks should be encouraged. Many practitioners also prescribe prophylactic antibiotics and antivirals to try and minimize risk of impetiginization and herpes simplex virus reactivation, which has been reported in $1.77 \%$ of patients after fractional nonablative lasers [67]. Patients should be instructed on postoperative signs of infection. These include development of yellowish exudate, eschar formation, and fevers/chills. If patients experience any of these symptoms their practitioner should be notified to consider obtaining a culture and instituting appropriate antibiotic therapy $[66,67]$.

Bruising may also occur after laser therapy and is most common with the pulsed dye lasers (PDL). Often this is used for maximal effect with PDL and generally does not remit for 1-2 weeks. It may be minimized by encouraging patient to avoid oral herbals and any anticoagulants not prescribed by a physician prior to the procedure. A double blind randomized placebo-controlled trial showed some improvement in severity of purpura, but not overall duration with the use of topical vitamin $\mathrm{K}$ cream [68]. Some efficacy in accelerating resolution of laser induced bruising has been observed with $5 \%$ topical vitamin $\mathrm{K}$ ointment and Arnica $20 \%$ ointment [69]. Counterintuitively, the PDL may be used at a nonbruising setting to help speed resolution.

Scarring is also possible with laser systems, and special care should be taken in sensitive areas that are more susceptible including: eyelids, neck, and chest. Multiple cases of extensive hypertrophic scarring resulting from fractional ablative $\mathrm{CO}_{2}$ laser therapy to the neck have been reported. These were most likely due to excessive fluences and spot densities used in this sensitive location [70].

\section{Conclusion}

Minimally invasive cosmetic procedures continue to grow in popularity, so it is imperative that practitioners have a thorough understanding of these treatment modalities to educate patients. Cosmetic providers also need to be fully aware of the risks posed by these elective procedures in order to recognize adverse events and treat them in an expedient manner. An in-depth knowledge of cosmetic procedures, products, and protocols is essential for trouble shooting and maximizing patient safety.

Conflict of Interest D Christiansen declares no conflicts of interest and $\mathrm{W}$ Stebbins declares no conflicts of interest.

\section{References}

Papers of particular interest, published recently, have been highlighted as:

- Of importance

-. Of major importance

1. Kremer J. New Survey Results from the ASDS Demonstrate Broad Scope of Practice for Dermatologic Surgeons. 2012; May 29, 2012:http://www.asds.net/2011-procedures/.

2. Glogau R, Kane M, Beddingfield F, et al. Onabotulinum toxin A: a meta-analysis of duration of effect in the treatment of glabellar lines. Dermatol Surg. 2012;38(11):1794-803.

3. Beer KR, Boyd C, Patel RK, Bowen B, James SP, Brin MF. Rapid onset of response and patient-reported outcomes after onabotulinum toxin A treatment of moderate-to-severe glabellar lines. J Drugs Dermatol. 2011;10(1):39-44.

4. Yu KC, Nettar KD, Bapna S, Boscardin WJ, Maas CS. Split-face double-blind study comparing the onset of action of onabotulinum toxin A and abobotulinum toxin A. Arch Facial Plast Surg. 2012;14 (3):198-204.

5. Botox Cosmetic [package insert]. Irvine, CA: Allergan, Inc.; 2012. 
6. Dysport [package insert]. Scottsdale, AZ: Medicis Aesthetics Inc.; 2012.

7. Myobloc [package insert]. South San Francisco, CA: Solstice Neurosciences, Inc.; 2010.

8. Xeomin [package insert]. Franklin, WI: Merz Pharmaceuticals, LLC.; 2011.

9. Information for Healthcare Professionals: Onabotulinum toxin A (marketed as Botox/Botox Cosmetic), Abobotulinum toxin A (marketed as Dysport) and Rimabotulinum toxin B (marketed as Myobloc). http://www.fda.gov/Drugs/DrugSafety/ PostmarketDrugSafetyInformationforPatientsandProviders/ DrugSafetyInformationforHeathcareProfessionals/ucm174949.htm Accessed 1/27/2013.

10. Alam M, Yoo SS, Wrone DA, White LE, Kim JY. Sterility assessment of multiple use botulinum A exotoxin vials: a prospective simulation. J Am Acad Dermatol. 2006;55(2):272-5.

11. Glick ZR, Vaphiades MS, Northington ME. Onabotulinum toxin A unmasking myasthenia gravis. Dermatol Surg. 2012.

12. Dressler D. Subclinical myasthenia gravis causing increased sensitivity to botulinum toxin therapy. J Neural Transm. 2010;117(11):1293-4.

13. - Allen SB, Goldenberg NA. Pain difference associated with injection of abobotulinum toxin A reconstituted with preserved saline and preservative-free saline: a prospective, randomized, side-by-side, double-blind study. Dermatol Surg. 2012;38(6):867-70. This study demonstrates the superiority of preservative containing saline for botulinum toxin reconstitution for pain control compared to the manufacturer recommended use of preservative free saline.

14. Cote TR, Mohan AK, Polder JA, Walton MK, Braun MM. Botulinum toxin type A injections: adverse events reported to the US Food and Drug Administration in therapeutic and cosmetic cases. J Am Acad Dermatol. 2005;53(3):407-15.

15. Brin MF, Boodhoo TI, Pogoda JM, et al. Safety and tolerability of onabotulinum toxin A in the treatment of facial lines: a meta-analysis of individual patient data from global clinical registration studies in 1678 participants. J Am Acad Dermatol. 2009;61(6):961-70.

16. Scheinfeld N. The use of apraclonidine eyedrops to treat ptosis after the administration of botulinum toxin to the upper face. Dermatol Online J. 2005;11(1):9.

17. Omoigui S, Irene S. Treatment of ptosis as a complication of botulinum toxin injection. Pain Med. 2005;6(2):149-51.

18. Crowner BE, Torres-Russotto D, Carter AR, Racette BA. Systemic weakness after therapeutic injections of botulinum toxin a: a case series and review of the literature. Clin Neuropharmacol. 2010;33(5):243-7.

19. Radiesse [package insert]. Franksville, WI: Merz Aesthetics, Inc.; 2012.

20. Wrinkle Fillers Approved by the Center for Devices and Radiological Health. http://www.fda.gov/MedicalDevices/ ProductsandMedicalProcedures/CosmeticDevices/WrinkleFillers/ ucm227749.htm.

21. Moers-Carpi M, Storck R, Howell DJ, Ogilvie P, Ogilvie A. Physician and patient satisfaction after use of calcium hydroxylapatite for cheek augmentation. Dermatol Surg. 2012;38(7 Pt 2):1217-22.

22. Beasley KL, Weiss MA, Weiss RA. Hyaluronic acid fillers: a comprehensive review. Facial Plast Surg. 2009;25(2):86-94.

23. Cohen JL. Understanding, avoiding, and managing dermal filler complications. Dermatol Surg. 2008;34 Suppl 1Suppl 1:S92-9.

24. Glogau RG, Kane MA. Effect of injection techniques on the rate of local adverse events in patients implanted with nonanimal hyaluronic acid gel dermal fillers. Dermatol Surg. 2008;34 Suppl 1:S105-9.

25. Wong WW, Gabriel A, Maxwell GP, Gupta SC. Bleeding risks of herbal, homeopathic, and dietary supplements: a hidden nightmare for plastic surgeons? Aesthet Surg J. 2012;32 (3):332-46.

26. Niamtu 3rd J. Filler pearls: refining the art of injection. Pract Dermatol. 2012;2012:23-6.
27. •• Sobanko JF, Miller CJ, Alster TS. Topical anesthetics for dermatologic procedures: a review. Dermatol Surg. 2012;38(5):709-21. Topical anesthetics are frequently used in cosmetic dermatology and Sobanko et al. provide a robust review that discusses the utility of these products and possible dangers associated with them.

28. Liu W, Yang X, Li C, Mo A. Adverse drug reactions to local anesthetics: a systematic review. Oral Surg Oral Med Oral Pathol Oral Radiol. 2012.

29. Topical Anesthetics - Full Version. http://www.fda.gov/Drugs/ DrugSafety/DrugSafetyPodcasts/ucm079047.htm.

30. Cox SE. Clinical experience with filler complications. Dermatol Surg. 2009;35 Suppl 2:1661-6.

31. • Beer K, Downie J, Beer J. A treatment protocol for vascular occlusion from particulate soft tissue augmentation. J Clin Aesthet Dermatol. 2012;5(5):44-7. This article discusses one of the most worrisome side effects of filler injections, vascular occlusion, and ways to address this complication. It is a must read for the cosmetic dermatologist.

32. Glaich AS, Cohen JL, Goldberg LH. Injection necrosis of the glabella: protocol for prevention and treatment after use of dermal fillers. Dermatol Surg. 2006;32(2):276-81.

33. • Lazzeri D, Agostini T, Figus M, Nardi M, Pantaloni M, Lazzeri S. Blindness following cosmetic injections of the face. Plast Reconstr Surg. 2012;129(4):995-1012. This comprehensive review discusses the reported cases of blindness resulting from filler injections and discusses possible ways to avoid this serious complication.

34. • Park SW, Woo SJ, Park KH, Huh JW, Jung C, Kwon OK. Iatrogenic retinal artery occlusion caused by cosmetic facial filler injections. Am J Ophthalmol. 2012;154(4):653-62 e651. Park et al. discuss the risks to ocular structures that may be associated with filler injections. It is important to understand the anatomy, possible danger zones, and techniques to reduce the risk for embolization.

35. Park HJ, Jung KH, Kim SY, Lee JH, Jeong JY, Kim JH. Hyaluronic acid pulmonary embolism: a critical consequence of an illegal cosmetic vaginal procedure. Thorax. 2010;65 (4):360-1.

36. Park KY, Son IP, Li K, Seo SJ, Hong CK. Reticulated erythema after nasolabial fold injection with hyaluronic acid: the importance of immediate attention. Dermatol Surg. 2011;37(11):1697-9.

37. Dayan SH, Arkins JP, Mathison CC. Management of impending necrosis associated with soft tissue filler injections. J Drugs Dermatol. 2011;10(9):1007-12.

38. Narins RS, Jewell M, Rubin M, Cohen J, Strobos J. Clinical conference: management of rare events following dermal fillers-focal necrosis and angry red bumps. Dermatol Surg. 2006;32(3):426-34.

39. Narins RS, Coleman 3rd WP, Glogau RG. Recommendations and treatment options for nodules and other filler complications. Dermatol Surg. 2009;35 Suppl 2:1667-71.

40. Brody HJ. Use of hyaluronidase in the treatment of granulomatous hyaluronic acid reactions or unwanted hyaluronic acid misplacement. Dermatol Surg. 2005;31(8 Pt 1):893-7.

41. • Lee A, Grummer SE, Kriegel D, Marmur E. Hyaluronidase. Dermatol Surg. 2010;36(7):1071-7. This review article focuses entirely on the utility of hyaluronidase for FDA approved and 'off label' indications. It is important for the cosmetic dermatologist to fully understand the utility of this product if planning to inject hyaluronic acid containing fillers.

42. Vitrase. [package insert] Irvine, CA: ISTA Pharmaceuticals, Inc.; 2004.

43. Hylenex. [package insert] San Diego, CA: Halozyme Therapeutics, Inc.; 2012.

44. Amphidase. [package insert] Rancho Cucamonga, CA: Amphastar Pharmaceuticals, Inc.; 2005.

45. Vartanian AJ, Frankel AS, Rubin MG. Injected hyaluronidase reduces restylane-mediated cutaneous augmentation. Arch Facial Plast Surg. 2005;7(4):231-7. 
46. - Niamtu 3rd J. Strategies to avoid and correct injectable filler complications. Pract Dermatol. 2011;2011:50-4. This article provides real world case presentations to address some of the most commonly experienced problems with filler injections. It is extremely useful for the cosmetic dermatologist faced with a filler complication.

47. Lowe NJ, Maxwell CA, Patnaik R. Adverse reactions to dermal fillers. Dermatol Surg. 2005;31(11 Pt 2):1616-25.

48. Gladstone HB, Cohen JL. Adverse effects when injecting facial fillers. Semin Cutan Med Surg. 2007;26(1):34.

49. Sclafani AP, Fagien S. Treatment of injectable soft tissue filler complications. Dermatol Surg. 2009;35 Suppl 2:1672-80.

50. - Monheit GD, Rohrich RJ. The nature of long-term fillers and the risk of complications. Dermatol Surg. 2009;35 Suppl 2:1598-604. Multiple cases of infectious complications resulting from fillers are presented and the role of biofilms is discussed in depth.

51. Cassuto D, Marangoni O, De Santis G, Christensen L. Advanced laser techniques for filler-induced complications. Dermatol Surg. 2009;35 Suppl 2:1689-95.

52. • Duffy DM. Sclerosants: a comparative review. Dermatol Surg. 2010;36 Suppl 2:1010-25. This high yield article provides an excellent overview of currently available sclerosants and is a must read for practitioners engaging in sclerotherapy.

53. Peterson JD, Goldman MP, Weiss RA, et al. Treatment of reticular and telangiectatic leg veins: double-blind, prospective comparative trial of polidocanol and hypertonic saline. Dermatol Surg. 2012;38 (8):1322-30.

54. Munavalli GS, Weiss RA. Complications of sclerotherapy. Semin Cutan Med Surg. 2007;26(1):22-8.

55. Scultetus AH, Villavicencio JL, Kao TC, et al. Microthrombectomy reduces postsclerotherapy pigmentation: multicenter randomized trial. J Vasc Surg. 2003;38(5):896-903.

56. Nootheti PK, Cadag KM, Magpantay A, Goldman MP. Efficacy of graduated compression stockings for an additional 3 weeks after sclerotherapy treatment of reticular and telangiectatic leg veins. Dermatol Surg. 2009;35(1):53-7. discussion $57-58$.
57. Tafazzoli A, Rostan EF, Goldman MP. Q-switched ruby laser treatment for postsclerotherapy hyperpigmentation. Dermatol Surg. 2000;26(7):653-6.

58. Forlee MV, Grouden M, Moore DJ, Shanik G. Stroke after varicose vein foam injection sclerotherapy. J Vasc Surg. 2006;43(1):162-4.

59. Meier B, Lock JE. Contemporary management of patent foramen ovale. Circulation. 2003;107(1):5-9.

60. Morrison N, Neuhardt DL. Foam sclerotherapy: cardiac and cerebral monitoring. Phlebology. 2009;24(6):252-9.

61. Sotradecol. [package insert] Queensbury, NY: Angiodynamics, Inc.; 2008.

62. Youker SR, Ammirati CT. Practical aspects of laser safety. Facial Plast Surg. 2001;17(3):155-63.

63. Dudelzak J, Goldberg DJ. Laser safety. Curr Probl Dermatol. 2011;42:35-9.

64. •- Lewin JM, Brauer JA, Ostad A. Surgical smoke and the dermatologist. J Am Acad Dermatol. 2011;65(3):636-41. This article provides a succinct review of an underappreciated work place hazard common to dermatologic offices. It raises awareness and provides helpful recommendations regarding ways to address surgical smoke.

65. Barrett WL, Garber SM. Surgical smoke: a review of the literature. Is this just a lot of hot air? Surg Endosc. 2003;17(6):979-87.

66. Alam M, Warycha M. Complications of lasers and light treatments. Dermatol Ther. 2011;24(6):571-80.

67. Alexiades-Armenakas MR, Dover JS, Arndt KA. Fractional laser skin resurfacing. J Drugs Dermatol. 2012;11(11):1274-87.

68. Shah NS, Lazarus MC, Bugdodel R, et al. The effects of topical vitamin $\mathrm{K}$ on bruising after laser treatment. J Am Acad Dermatol. 2002;47(2):241-4.

69. Leu S, Havey J, White LE, et al. Accelerated resolution of laserinduced bruising with topical $20 \%$ arnica: a rater-blinded randomized controlled trial. Br J Dermatol. 2010;163(3):557-63.

70. Avram MM, Tope WD, Yu T, Szachowicz E, Nelson JS. Hypertrophic scarring of the neck following ablative fractional carbon dioxide laser resurfacing. Lasers Surg Med. 2009;41(3):185-8. 